\title{
Vertebral Size in Elderly Women with Osteoporosis Mechanical Implications and Relationship to Fractures
}

\author{
Vicente Gilsanz, * M. Luiza Loro, * Thomas F. Roe, „ James Sayre, ${ }^{5}$ Ramon Gilsanz," and Eloy E. Schulz' \\ ${ }^{*}$ Department of Radiology and ${ }^{\ddagger}$ Pediatrics, Childrens Hospital Los Angeles, University of Southern California School of Medicine, Los \\ Angeles, California 90027; 'Department of Radiological Sciences and Biostatistics, University of California Los Angeles School of \\ Medicine, Los Angeles, California 90024; "Gilsanz Murray Steficek Structural Engineers, New York 10003; and 'Department of \\ Radiology, Loma Linda University Medical Center, Loma Linda, California 92354
}

\begin{abstract}
Reductions in bone density are a major determinant of vertebral fractures in the elderly population. However, women have a greater incidence of fractures than men, although their spinal bone densities are comparable. Recent observations indicate that women have $20-25 \%$ smaller vertebrae than men after accounting for differences in body size. To assess whether elderly women with vertebral fractures have smaller vertebrae than women who do not experience fractures, we reviewed 1,061 computed tomography bone density studies and gathered 32-matched pairs of elderly women, with reduced bone density, whose main difference was absence or presence of vertebral fractures. Detailed measurements of the dimensions of unfractured vertebrae and the moment arm of spinal musculature from T12 to L4 were calculated from computed tomography images in the 32 pairs of women matched for race, age, height, weight, and bone density. The cross-sectional area of unfractured vertebrae was $4.9-11.5 \%\left(10.5 \pm 1.4\right.$ vs $9.7 \pm 1.5 \mathrm{~cm}^{2} ; P$ $<0.0001$ ) smaller and the moment arm of spinal musculature was 3.2-7.4\% (56.4 \pm 5.1 vs $53.1 \pm 4.4 \mathrm{~mm} ; P<0.0001)$ shorter in women with fractures, implying that mechanical stress within intact vertebral bodies for equivalent loads is $5-17 \%$ greater in women with fractures compared to women without fractures. Such significant variations are very likely to contribute to vertebral fractures in osteoporotic women. (J. Clin. Invest. 1995. 95:2332-2337.) Key words: osteoporosis • fractures $\bullet$ bone size $\bullet$ bone density • computed tomography
\end{abstract}

\section{Introduction}

Osteoporosis is a disease characterized by low bone mass and the development of nontraumatic fractures, most commonly in the spine (1). Approximately 500,000 elderly women in the United States are newly diagnosed with vertebral fractures every year due to the inability of the vertebral body to withstand the loads associated with normal daily activities as skeletal mass

Address correspondence to Vicente Gilsanz, Department of Radiology, Children's Hospital Los Angeles, 4650 Sunset Blvd., \#81, Los Angeles, CA 90027. Phone: 213-669-4571; FAX: 213-666-7816.

Received for publication 31 October 1994 and in revised form 22 December 1994.

J. Clin. Invest.

(c) The American Society for Clinical Investigation, Inc.

$0021-9738 / 95 / 05 / 2332 / 06 \$ 2.00$

Volume 95, May 1995, 2332-2337 and bone strength decline with aging $(1,2)$. Of the two components of vertebral bone mass (bone density and bone size) cancellous vertebral bone density is known to be a major determinant of vertebral fracture (3-5), while the prevailing view is that vertebral size is mainly related to body size and does not contribute to vertebral fractures (6). However, bone density alone is not a sufficient explanation for vertebral fractures: many women with low spinal bone density do not experience fractures, and there is substantial overlap in bone density between women with and without radiographic evidence of vertebral compression (3-5). In an attempt to understand why some women with low bone density do not have fractures, other properties of bone that contribute to its strength, such as the quality of the material and its three-dimensional arrangement, are being considered in the pathogenesis of osteoporotic fractures $(7,8)$. Few studies, however, have examined the role of bone size as a possible determinant of vertebral fractures (9).

There is a four- to sevenfold higher incidence of vertebral fractures in elderly women as compared to men despite recent in vitro and in vivo evidence that their spinal bone densities are comparable (10-13). Studies using quantitative computed tomography (QCT) ${ }^{1}$ to measure the size and density of vertebrae indicate that the cross-sectional area of vertebrae in women is $\sim 20-25 \%$ smaller than in men, even after accounting for differences in body size (13). The degree to which gender differences in vertebral size contribute to the greater incidence of vertebral fractures in women remains to be determined. Nevertheless, differences in vertebral cross-sectional area have important biomechanical implications with respect to the loading capacity of the spine and they could account for variations in fracture incidence that are not attributable to reductions in cancellous vertebral bone density (13). In this study we examined whether elderly women with reduced bone density and vertebral fractures have smaller vertebral bodies and are under greater mechanical stress than women of the same age, body habitus, and bone density, who do not experience vertebral fractures.

\section{Methods}

Identification of patients for study. From December, 1985 through March, 1992, 1,061 patients had computed tomography (CT) bone density studies at the Department of Radiology of Loma Linda University, Loma Linda, CA and completed a questionnaire which included information about their race or ethnic background, age, height, weight, diet, physical activity, and health status. From these questionnaires we selected postmenopausal Caucasian women, $60 \mathrm{yr}$ of age or older, who

1. Abbreviations used in this paper: CT, computed tomography; QCT, quantitative computed tomography. 
Table I. Characteristics of 232 Elderly Women with and without Vertebral Fractures*

\begin{tabular}{lccc}
\hline & $\begin{array}{c}\text { Without fracture } \\
(n=148)\end{array}$ & $\begin{array}{c}\text { With fracture } \\
(n=84)\end{array}$ & $\begin{array}{c}P \\
\text { value* }\end{array}$ \\
\hline $\begin{array}{l}\text { Cancelous bone density } \\
\quad\left(\mathrm{gm} / \mathrm{cm}^{3}\right)\end{array}$ & $68.8 \pm 21.6$ & $49.4 \pm 26.1$ & $<0.0001$ \\
Age $(\mathrm{yr})$ & $70.2 \pm 6.7$ & $74.2 \pm 6.4$ & $<0.0001$ \\
Height $(\mathrm{cm})$ & $159.7 \pm 8.1$ & $156.9 \pm 10.0$ & $<0.05$ \\
Weight $(\mathrm{kg})$ & $59.9 \pm 12.5$ & $57.7 \pm 13.0$ & $\mathrm{NS}$ \\
\hline
\end{tabular}

Values are mean $\pm \mathrm{SD}$. ${ }^{*}$ Probabilites determined using the unpaired $t$ test.

were ambulatory, not taking any medication on a regular basis (including oral calcium supplements, vitamins, fluoride, and estrogen preparations), and without history of hip fracture or of any chronic illness that could result in bone loss. Using these criteria we identified 727 women and subsequently we reviewed their CT bone density studies.

Data from 265 bone density studies were excluded for the following reasons: missing $(n=97)$, deteriorated $(n=48)$, or incomplete $(n$ $=12$ ) CT exams and/or scanning settings other than $140 \mathrm{mAs}, 120$ $\mathrm{kVp}, 2 \mathrm{~s}$, and 10 -mm section thickness $(n=108)$. In addition, to permit valid comparisons between bone density measurements, records for 184 examinations using other than the CT-T 9800 scanner (General Electric Co., Milwaukee, WI) and calibration phantom (Image Analysis, Inc., Columbia, KY) were eliminated.

The remaining $278 \mathrm{CT}$ bone density studies were reviewed to identify women with cancellous bone density below $110 \mathrm{mg} / \mathrm{cm}^{3}$. Current criteria suggests that osteoporosis be defined as a condition wherein the value for bone mineral density is $>2.5$ SD below the young adult mean value (14). Previous studies indicate that nontraumatic vertebral fractures occur predominantly in patients with QCT measurements for cancellous bone density $<110 \mathrm{mg} / \mathrm{cm}^{3}$, which corresponds $\sim$ to 2.5 SD below peak bone density $(13,15)$. For this reason, 30 women with cancellous bone density $>110 \mathrm{mg} / \mathrm{cm}^{3}$ were excluded from further evaluation as they did not have osteoporosis nor were they at risk for fracture.

Because there are no generally accepted guidelines to diagnose vertebral fractures (16), anteroposterior and lateral CT spine radiographs of the 248 remaining women were independently reviewed by two radiologists to determine the presence or absence of fractures in the vertebral bodies based on the following criteria: wedge fractures were identified by a reduction in anterior height compared to posterior height; central collapse fractures by a loss of height in the mid-portion of the vertebral body compared with either the anterior or posterior height; and crush fractures by a reduction in both the anterior and posterior height when compared with the closest adjacent intact vertebrae. 16 women were excluded on the basis that they had fractures in all five vertebrae ( $n$ $=6$ ), scoliosis $20^{\circ}$ or greater $(n=7)$, or the opinion between radiologists about the diagnosis differed $(n=3)$.

Of the remaining 232 Caucasian women, $60 \mathrm{yr}$ or older, with cancellous vertebral bone density below the fracture threshold of $110 \mathrm{mg} /$ $\mathrm{cm}^{3}, 148$ had no evidence of vertebral compression while 84 had one or more vertebral fractures. On average, women with one or more fractures had lower cancellous bone density, were older, and shorter, than women without fractures, corroborating previous investigations indicating that reductions in bone density with aging are important in the pathogenesis of vertebral fractures (2-5) and that vertebral fractures lead to loss of height (17) (Table I). There was, however, considerable overlap among the values for cancellous bone density in those with and without fractures (Fig. 1). To eliminate the confounding effect that age, bone density, and anthropometric variables may have on the pathogenesis of vertebral fractures and/or on the size of the bones, a subset of patients from each group was matched within 12 mo of age and within
A

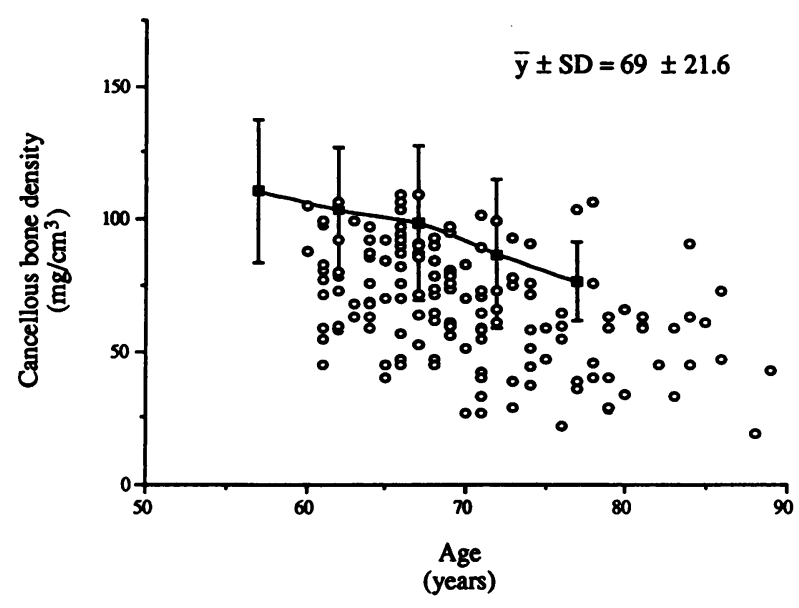

B

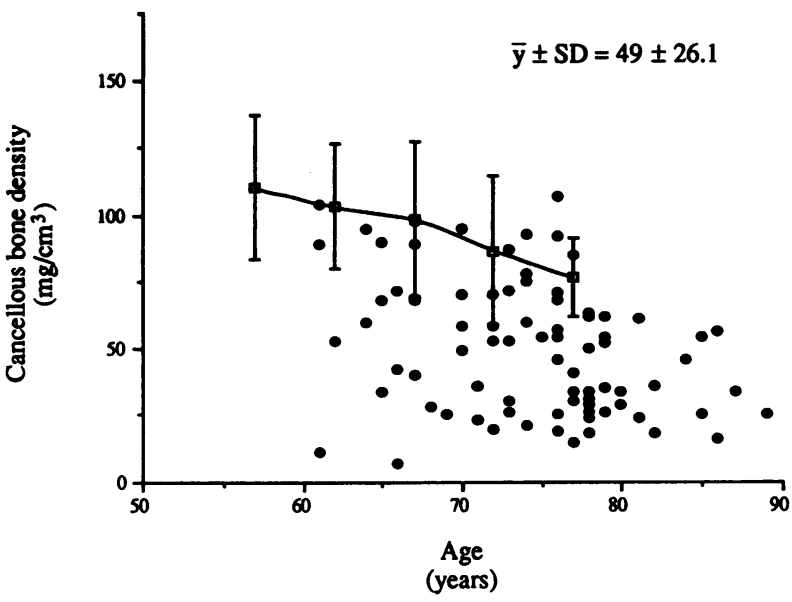

Figure 1. Cancellous vertebral bone density in women with spinal osteoporosis, with and without vertebral fractures. Cancellous vertebral bone density measured by QCT, in 148 women without $(A)$ and 84 women with $(B)$ vertebral fracture. Values for cancellous bone density represent the mean measurement for all five vertebral bodies in women without fractures and the average of one or more unfractured vertebral bodies in women with fractures. Normative data for cancellous vertebral density according to age (mean $\pm 1 \mathrm{SD}$ ) are provided from reference 15 ; it should be noted that most women above the age of 60 have osteoporosis (defined as bone density values 2.5 SD below peak bone density, reference 14) and QCT values below the threshold for spontaneous vertebral fracture (110 $\left.\mathrm{mg} / \mathrm{cm}^{3} \mathrm{~K}_{2} \mathrm{HPO}_{4}\right)(2-5)$.

$5 \%$ of body height, weight, and cancellous vertebral bone density. Using this approach we identified a total of 32 unique matched pairs of women whose main difference was the presence or absence of vertebral fractures.

Measurements by quantitative computed tomography. The cortical vertebral bone density, the cross-sectional area, and the height of all unfractured vertebral bodies, from $\mathrm{T} 12$ to $\mathrm{L} 4$, were determined directly from CT images in the 32 pairs of women as previously described $(13,18)$. In addition, the corresponding moment arm of the spinal musculature, defined as the distance from the vertebral body to the projected center of the erector spinae muscle, was also measured from the same images $(13,19)$. All measurements were done only in vertebral bodies without fracture. The coefficients of variation for cortical vertebral bone density, vertebral cross-sectional area, vertebral body height, and the moment arm of spinal musculature, previously calculated from three repeated determinations in five subjects at the five vertebral levels, were $1,1.7,1.6$, and $1.5 \%$, respectively. 


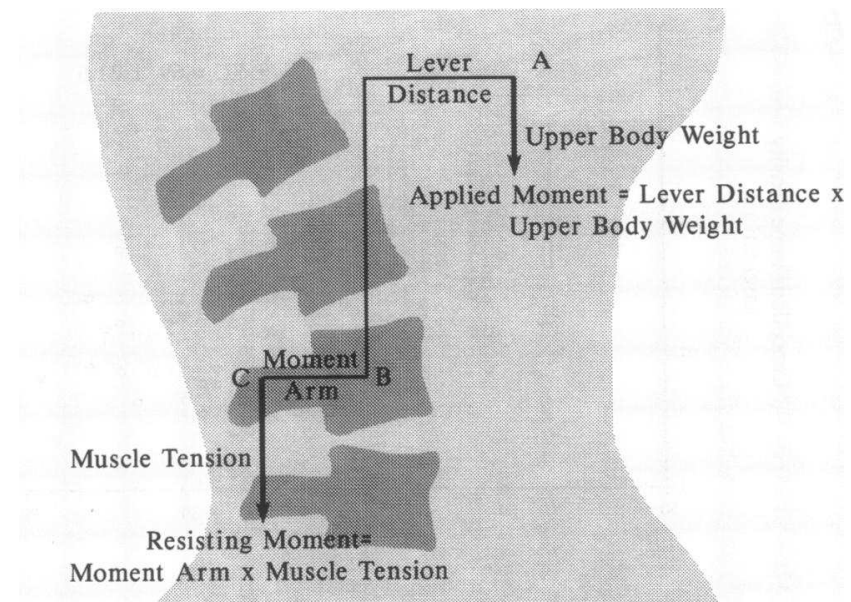

Compressive Force in Bone $=$ Muscle Tension + Upper Body Weight

Figure 2. Biomechanics of the vertebral body. The compressive force within the vertebral body during bending results from two equal and opposing moments (equations 1 and 2). A decrease in the moment arm between the center of the erector spinae musculature $(A)$ and the center of the vertebral body $(B)$ requires more muscle tension to maintain equilibrium, resulting in a higher compressive stress in the vertebral body (equation 3 ).

Resisting moment $=$ applied moment

Muscle tension $\times$ moment arm

$=$ upper body weight $\times$ lever distance

Muscle tension $=\frac{\text { upper body weight } \times \text { lever distance }}{\text { moment arm }}$

During axial compression alone, the center of gravity of the upper body $(C)$ is directly above $B$; thus the moment arm for the applied moment is zero, and there is no resisting bending moment. Under these conditions, axial compressive stress within the vertebral body is inversely related to the area of compression (equation 4 ).

Axial compressive stress $=\frac{\text { upper body weight }}{\text { vertebral body area }}$

(Gilsantz, V., M. I. Boechat, R. Gilsanz, M. L. Loro, T. F. Roe, and W. G. Goodman. 1994. Gender differences in vertebral size in adults: biomechanical implications. Radiology. 190:678-683.)

Table II. Characteristics of 32 Pairs of Caucasian Women with and without Vertebral Fractures Who Were Matched for Age, Height, Weight, and Cancellous Vertebral Bone Density

\begin{tabular}{lccc}
\hline & $\begin{array}{c}\text { Without fracture } \\
(\mathrm{n}=32)\end{array}$ & $\begin{array}{c}\text { With fracture } \\
(\mathrm{n}=32)\end{array}$ & $\begin{array}{c}P \\
\text { value* }\end{array}$ \\
\hline $\begin{array}{l}\text { Cancellous bone density } \\
\quad\left(\mathrm{gm} / \mathrm{cm}^{3}\right)\end{array}$ & & & \\
Age $(\mathrm{yr})$ & $57 \pm 21.5$ & $56 \pm 23.5$ & $\mathrm{NS}$ \\
Height $(\mathrm{cm})$ & $72.7 \pm 6.57$ & $72.9 \pm 6.43$ & $\mathrm{NS}$ \\
Weight $(\mathrm{kg})$ & $159.9 \pm 8.14$ & $157.1 \pm 6.10$ & $\mathrm{NS}$ \\
& $59.1 \pm 15.80$ & $58.8 \pm 13.08$ & $\mathrm{NS}$ \\
& & & \\
\end{tabular}

Values are mean \pm SD. * Probabilities determined using the paired $t$ test.
Table III. Cancellous and Cortical Bone Densities of Intact Vertebral Bodies in 32 Pairs of Women with [Fx(+)] and without [Fx(-)] Fracture

\begin{tabular}{|c|c|c|c|c|c|c|}
\hline \multirow[b]{2}{*}{ Vertebral level } & \multicolumn{3}{|c|}{ Cancellous Bone Density } & \multicolumn{3}{|c|}{ Cortical Bone Density } \\
\hline & $\mathbf{F x}(-)$ & $\mathbf{F x}(+)$ & $\begin{array}{c}P \\
\text { value* }\end{array}$ & $\mathbf{F x}(-)$ & $\mathbf{F x}(+)$ & $\begin{array}{c}P \\
\text { value* }\end{array}$ \\
\hline $\mathrm{T} 12(n=12)$ & $76 \pm 15$ & $76 \pm 16$ & NS & $331 \pm 70$ & $347 \pm 109$ & NS \\
\hline $\mathrm{L1}(n=16)$ & $64 \pm 20$ & $70 \pm 30$ & NS & $345 \pm 74$ & $330 \pm 68$ & NS \\
\hline L2 $(n=26)$ & $57 \pm 24$ & $58 \pm 29$ & NS & $354 \pm 113$ & $359 \pm 72$ & NS \\
\hline $\mathrm{L} 3(n=23)$ & $52 \pm 20$ & $50 \pm 23$ & NS & $331 \pm 77$ & $329 \pm 69$ & NS \\
\hline $\mathrm{L} 4(n=27)$ & $50 \pm 26$ & $48 \pm 28$ & NS & $342 \pm 82$ & $332 \pm 69$ & NS \\
\hline All $(n=104)$ & $58 \pm 23$ & $58 \pm 27$ & NS & $346 \pm 71$ & $339 \pm 73$ & NS \\
\hline
\end{tabular}

$n$, Number of paired intact vertebral bodies compared at the designated level. Values are mean $\pm \mathrm{SD}\left(\mathrm{mg} / \mathrm{cm}^{3} \mathrm{~K}_{2} \mathrm{HOP}_{4}\right)$. * Probabilities determined using the paired $t$ test.

Differences in mechanical stress during axial loading were calculated as the ratio of the cross-sectional areas between women without and with fractures. Differences in mechanical stress during bending were calculated as the product of the ratios of the cross-sectional areas $\times$ the ratios of the moment arms of the spinal musculature between women without and with fractures $(13,20,21)$ (Fig. 2).

Additionally, estimates of mechanical stress during axial loading and during bending between adjacent vertebral levels (T12 and L1, L1 and L2, L2 and L3, L3 and L4) were calculated for the 32 women without fractures.

Statistical analysis. All results are expressed as the mean \pm 1 SD. Statistical evaluation of the data was done using the Student's $t$ test for either unpaired or paired samples (22), or its multivariate analogue, the Hotelling's $T^{2}(23)$.

\section{Results}

By design, there was no difference in the age, cancellous bone density, and anthropometric variables in the subset of 32 matched pairs of women whose main difference was the presence or absence of vertebral fractures (Table II). A total of 56 fractures was present in the 32 women with fractures: 39 of these were wedge fractures, 11 were crush fractures and 6 vertebrae had central collapse. 17 women had 1 fracture, 8 women

Table IV. Height of Intact Vertebral Bodies in 32 Pairs of Women with $[F x(+)]$ and without $[F x(-)]$ Fracture

\begin{tabular}{lccc}
\hline & \multicolumn{3}{c}{ Height } \\
\cline { 2 - 4 } Vertebral level & Fx(-) & Fx(+) & $P$ value* \\
\hline T12 $(n=12)$ & $2.31 \pm 0.14$ & $2.27 \pm 0.18$ & NS \\
L1 $(n=16)$ & $2.42 \pm 0.16$ & $2.44 \pm 0.14$ & NS \\
L2 $(n=26)$ & $2.53 \pm 0.18$ & $2.48 \pm 0.20$ & NS \\
L3 $(n=23)$ & $2.56 \pm 0.17$ & $2.50 \pm 0.22$ & NS \\
L4 $(n=27)$ & $2.56 \pm 0.21$ & $2.51 \pm 0.23$ & NS \\
All $(n=104)$ & $2.48 \pm 0.37$ & $2.44 \pm 0.38$ & NS \\
\hline
\end{tabular}

$n$, Number of paired intact vertebral bodies compared at the designated level. Values are mean \pm SD. ${ }^{*}$ Probabilities determined using the paired $t$ test. Values for vertebral body height represent the average of the anterior, middle, and posterior heights of unfractured vertebral bodies. 
Table V. Vertebral Cross-sectional Area and Moment Arm of Spinal Musculature in 32 Pairs of Women with [Fx(+)] and without $[F x(-)]$ Fracture

\begin{tabular}{|c|c|c|c|c|c|c|}
\hline \multirow[b]{2}{*}{ Vertebral level } & \multicolumn{3}{|c|}{ Cross-sectional area $\left(\mathrm{cm}^{2}\right)$} & \multicolumn{3}{|c|}{ Moment arm (mm) } \\
\hline & $\mathbf{F x}(-)$ & $\mathbf{F x}(+)$ & $P$ value* & $\mathbf{F x}(-)$ & $\mathbf{F x}(+)$ & $P$ value* \\
\hline $\mathrm{T} 12(n=12)$ & $9.22 \pm 1.05$ & $8.42 \pm 1.40$ & 0.08 & $49.17 \pm 2.70$ & $46.96 \pm 4.44$ & 0.050 \\
\hline $\mathrm{L} 1(n=16)$ & $9.78 \pm 0.90$ & $8.66 \pm 1.10$ & 0.007 & $52.68 \pm 3.69$ & $50.97 \pm 2.89$ & 0.038 \\
\hline $\mathrm{L} 2(n=26)$ & $10.02 \pm 1.16$ & $9.27 \pm 1.35$ & 0.042 & $55.82 \pm 3.86$ & $52.06 \pm 3.36$ & 0.0001 \\
\hline L3 $(n=23)$ & $10.96 \pm 1.24$ & $10.42 \pm 1.35$ & 0.17 & $58.30 \pm 3.14$ & $55.40 \pm 2.77$ & 0.0001 \\
\hline L4 $(n=27)$ & $11.65 \pm 1.09$ & $10.73 \pm 1.18$ & 0.005 & $60.60 \pm 4.16$ & $56.13 \pm 3.28$ & 0.0001 \\
\hline All $(n=104)$ & $10.52 \pm 1.38$ & $9.71 \pm 1.54$ & 0.0001 & $56.35 \pm 5.15$ & $53.09 \pm 4.40$ & 0.0001 \\
\hline
\end{tabular}

$n$, Number of paired intact vertebral bodies compared at the designated level. Values are mean \pm SD. * Probabilities determined using the paired $t$ test. Significant differences were also found using the cross-sectional area of the vertebrae from T12 to L4 as a vector of observations, Hotelling's $\mathrm{T}^{2}$ test $(P<0.003)$. Similarly, using the moment arms from T12 to $\mathrm{L} 4$ as a vector of observations, the Hotelling's $\mathrm{T}^{2}$ test yields a significant result $(P<0.0001)$.

had 2, 5 had 3, and 2 had 4. The number of fractures at each vertebral level was 20 at T12, 16 at $\mathrm{L} 1,6$ at $\mathrm{L} 2,9$ at $\mathrm{L} 3$, and 5 at L4.

In this subgroup of 32 matched pairs, there was no difference in the cortical bone density (Table III) or in the height of unfractured vertebral bodies at any vertebral level (Table IV). In contrast to these findings, the cross-sectional area of unfractured vertebral bodies was found to be significantly smaller in the 32 women with fractures, compared with their matched counterparts, at $\mathrm{L} 1, \mathrm{~L} 2$, and $\mathrm{L} 4$ vertebral levels and when all unfractured vertebrae from $\mathrm{T} 12$ to $\mathrm{L} 4$ were considered together (Table V). Substantial differences were also found using the cross-sectional area of the vertebrae from $\mathrm{T} 12$ to $\mathrm{L} 4$ as a vector of observations; Hotelling's $\mathrm{T}^{2}$ test $(P<0.003)$ (Table V). On average, the cross-sectional area of unfractured vertebral bodies was $7.7 \%$ smaller in women with fractures as compared with women without fractures (Table VI).

Similar to the findings for area, the moment arm between the center of unfractured vertebral bodies and the center of the erector spinae muscle was found to be significantly smaller in women with fractures compared with their matched counterparts both using Student's $t$ tests $(P<0.0001)$ or its multivariate

Table VI. Percent Differences in Vertebral Cross-sectional Area, Moment Arm of Spinal Musculature, and Mechanical Stress of Intact Vertebral Bodies in 32 Pairs of Women with and without fracture

\begin{tabular}{lccccc}
\hline & & & \multicolumn{2}{c}{$\begin{array}{c}\text { Mechanical stress } \\
\text { (\% difference) }\end{array}$} \\
\cline { 4 - 5 } Vertebral level & $\begin{array}{c}\text { Cross-sectional area } \\
\text { (\% difference) }\end{array}$ & $\begin{array}{c}\text { Moment arm } \\
\text { (\% difference) }\end{array}$ & $\begin{array}{c}\text { Axial } \\
\text { compression }\end{array}$ & Bending \\
\hline T12 $(n=12)$ & 8.7 & 4.5 & 10 & 15 \\
L1 $(n=16)$ & 11.5 & 3.2 & 13 & 17 \\
L2 $(n=26)$ & 7.5 & 6.7 & 8 & 16 \\
L3 $(n=23)$ & 4.9 & 5.0 & 5 & 11 \\
L4 $(n=27)$ & 7.9 & 7.4 & 9 & 17 \\
All $(n=104)$ & 7.7 & 5.8 & 8 & 15 \\
\hline
\end{tabular}

$n$, Number of paired intact vertebral bodies compared at the designated level. analogue the Hotelling's $\mathrm{T}^{2}$ test $(P<0.0001)$ (Table V). On average, the moment arm was $5.8 \%$ smaller in women with fractures as compared with women without fractures (Table VI). The overall correlation between measurements of crosssectional area and moment arm of spinal musculature was 0.60 $(P<0.0001)$.

Based on cross-sectional area and moment arm values, estimates of mechanical stress were obtained for women with and without fractures. Mean differences in mechanical stress for equivalent loads within the intact lumbar vertebral bodies were calculated to be $8 \%(10.52 / 9.71=1.08)$ greater during axial loading and $15 \%([10.52 / 9.71] \times[56.35 / 53.09]=1.15)$ greater during bending in women with fractures than in women without fractures (Table VI).

Differences in cross-sectional area, moment arm, and mechanical stress between women with and without fractures were, on average, greater than the difference that normally exists in these parameters between adjacent vertebral levels (Table VII).

\section{Discussion}

The results of the current study indicate that small vertebral size contributes to the development of vertebral fractures in women already at risk for fractures. The cross-sectional area of the vertebral body was smaller in women with osteoporosis and

Table VII. Percent Differences in Vertebral Cross-sectional Area, Moment Arm of Spinal Musculature and Mechanical Stress Between Adjacent Vertebral Levels in 32 Women without Vertebral Fracture

\begin{tabular}{lcccc}
\hline & & & \multicolumn{2}{c}{$\begin{array}{c}\text { Mechanical stress } \\
\text { (\% difference) }\end{array}$} \\
\cline { 4 - 5 } $\begin{array}{c}\text { Vertebral } \\
\text { level }\end{array}$ & $\begin{array}{c}\text { Cross-sectional area } \\
\text { (\% difference) }\end{array}$ & $\begin{array}{c}\text { Moment arm } \\
\text { (\% difference) }\end{array}$ & $\begin{array}{c}\text { Axial } \\
\text { compression }\end{array}$ & Bending \\
\hline T12-L1 & 4.1 & 6.3 & 4 & 11 \\
L1-L2 & 6.3 & 5.5 & 7 & 13 \\
L2-L3 & 7.7 & 4.2 & 8 & 13 \\
L3-L4 & 5.0 & 3.2 & 5 & 9 \\
Average & 5.8 & 4.8 & 6 & 11 \\
\end{tabular}




\begin{tabular}{|c|c|c|c|c|c|c|}
\hline \multirow[b]{2}{*}{ Vertebral level } & \multicolumn{2}{|c|}{ Anterior } & \multicolumn{2}{|c|}{ Middle } & \multicolumn{2}{|c|}{ Posterior } \\
\hline & $F \times(-)$ & $\mathrm{Fx}(+)$ & $F x(-)$ & $\mathrm{Fx}(+)$ & $F x(-)$ & $\mathrm{Fx}(+)$ \\
\hline $\mathrm{T} 12(n=20)$ & $2.19 \pm 0.22$ & $16.4 \pm 0.41 \ddagger$ & $2.00 \pm 0.25$ & $1.36 \pm 0.42 \ddagger$ & $2.35 \pm 0.25$ & $2.36 \pm 0.186$ \\
\hline L1 $(n=16)$ & $2.46 \pm 0.19$ & $1.85 \pm 0.27 \ddagger$ & $2.20 \pm 0.19$ & $1.36 \pm 0.39 \ddagger$ & $2.57 \pm 0.20$ & $2.40 \pm 0.22 *$ \\
\hline $\mathrm{L} 2(n=6)$ & $2.65 \pm 0.14$ & $1.93 \pm 0.67$ & $2.30 \pm 0.17$ & $1.45 \pm 0.51 *$ & $2.58 \pm 0.12$ & $2.42 \pm 0.31$ \\
\hline $\mathrm{L} 3(n=9)$ & $2.77 \pm 0.21$ & $2.20 \pm 0.44 *$ & $2.49 \pm 0.16$ & $1.77 \pm 0.43 *$ & $2.86 \pm 0.16$ & $2.55 \pm 0.22 *$ \\
\hline $\mathrm{L} 4(n=5)$ & $2.70 \pm 0.13$ & $2.30 \pm 0.41$ & $2.64 \pm 0.21$ & $1.34 \pm 0.27 *$ & $2.42 \pm 0.18$ & $2.32 \pm 0.38$ \\
\hline All $(n=56)$ & $2.44 \pm 0.28$ & $1.89 \pm 0.45 \ddagger$ & $2.20 \pm 0.28$ & $1.45 \pm 0.44 \ddagger$ & $2.55 \pm 0.28$ & $2.39 \pm 0.23 *$ \\
\hline
\end{tabular}

$n$, Number of paired vertebrae compared at the designated level. Values are mean \pm SD. ${ }^{*} P<0.05 .{ }^{\ddagger} P<0.0001$.

vertebral fractures than in women of the same age without fractures (Tables V and VI). This difference was found from measurements obtained solely from unfractured vertebral bodies, thus, the results cannot be ascribed to deformities arising from vertebral compression. Because subjects with and without fracture were matched for height and weight before the size of the vertebral body was measured, it is unlikely that variations in body habitus account for the current findings (Table II). Similarly, our findings cannot be attributed to reductions in bone density, as neither cancellous nor cortical bone density in the spine differed between groups (Table III).

Only clinical radiographic criteria were used to diagnose vertebral fractures in the current study. Although more rigorous parameters for the diagnosis of vertebral fractures have been proposed (16), widespread acceptance and application of these criteria have yet to be adapted. It should be noted, however, that the severity of vertebral deformity for subjects with fractures in the current study was substantial, as judged by the magnitude of the discrepancies in height for the anterior, middle, and posterior portions of the vertebral body in the 32-matched pairs of women (Table VIII). Furthermore, all fractured vertebrae had at least $20 \%$ reduction in anterior, middle, and/or posterior vertebral body height.

Our findings corroborate numerous in vitro studies indicating that the compressive strength of the vertebra is determined not only by its bone density $(13,24-30)$, but also by its crosssectional area $(13,30,31)$. The cross-sectional area of vertebral bodies is designed to bear mechanical loads that are progressively larger caudally as the superimposed weight of the upper body increases. In the present study, the values for the crosssectional area from $\mathrm{T} 12$ to $\mathrm{L} 4$ increased in all subjects, while, simultaneously, cancellous bone density decreased and cortical bone density remained unchanged, underscoring the importance of vertebral size to meet increasing loads (Tables III and V).

The smaller vertebral size in women with fractures results in greater mechanical stress for all normal physical activities. Mechanical stress within the vertebrae arise from axial compressive forces and from bending forces; the magnitude of each type of stress varies with posture and with orientation of vertebral bodies within the spinal column. Compressive stress within bone during axial loading varies inversely with cross-sectional area $(13,20,21)$ (Fig. 2). For example, the relative compressive stress within two vertebral bodies that differ in cross-sectional area by $10 \%$ is $1 / 0.9$, or 1.11 , times greater in the smaller bone with an equivalent applied mechanical load. In the current study, the average difference in the cross-sectional area of intact vertebrae between women with and without fractures was $7.7 \%$ (Table VI). This disparity corresponds to an $8.3 \%$ greater stress during axial compression, for an equivalent applied load, in the intact vertebrae of women with fractures (Table VI).

Even greater discrepancies in mechanical stress occur during the application of bending forces in vertebrae of different size. The applied moment is a function of upper body weight and lever distance and is opposed by an equal resisting moment which is a function of the moment arm and the tension generated by paraspinous musculature $(13,31,32)$ (Fig. 2$)$. In the present study, the moment arm was, on average, $5.8 \%$ smaller in the paired subjects with fracture; implying that for an equivalent load, mechanical stress during bending was $15 \%$ greater in the intact vertebral bodies of women with fractures (Table VI).

It should be noted that differences in vertebral cross-sectional area, moment arm of spinal musculature, and mechanical stress between women with and without fractures are, on average, greater than the differences that normally exist in these parameters between adjacent vertebral levels in elderly women (Table VII).

The mechanism responsible for the smaller cross-sectional area in women with spinal fracture is not known. Although in this study we did not rigorously control for diet or physical activity, variables known to affect the rate of decline of bone mass with aging $(1,17)$, it is unlikely that these factors account for the smaller vertebral cross-sectional area noted in women with fracture. In elderly women little, if any, bone is gained from the periosteal surface of vertebral bone, and the overall circumference of their vertebrae remains stable (11). The variations in vertebral body dimensions found in this study are therefore more likely to reflect differences in bone growth that evolve during skeletal development.

Current studies suggest that vertebral fractures in elderly women may result from insufficient bone acquisition during childhood and a relatively low peak bone mass (33). The amount of bone gained during growth is largely genetically regulated, possibly by an allelic change in the receptor for 1,25 dihydroxy-vitamin D (34). Recent observations in children and adolescents also indicate that variations in vertebral size and not vertebral density account for gender difference in vertebral peak bone mass (35). Whether genetic factors or other determinants of peak bone mass, such as physical activity, regulate the size and/or the density of the vertebral bone is yet to be established.

In conclusion, vertebral size is an important determinant of vertebral fracture in elderly women with osteoporosis. The 
smaller cross-sectional area of the vertebral bodies imparts a mechanical disadvantage that increases the stress within the spine and becomes increasingly important as bone density declines with age. Future studies are required to ascertain the relative significance of bone size and bone density in predicting the probability of vertebral fractures in women with osteoporosis.

\section{Acknowledgments}

The authors would like to thank Cara L. Beck for her technical assistance and comments on this manuscript.

Supported in part by a grant (RO1-AR4-1853-01A1) from the National Institute of Arthritis and Musculoskeletal and Skin Diseases.

\section{References}

1. Kleerekoper, M., and L. V. Avioli. 1993. Evaluation and treatment of postmenopausal osteoporosis. In Primer on the Metabolic Bone Diseases and Disorders of Mineral Metabolism. 2nd ed. Raven Press, Ltd., New York. 223229.

2. Melton, L. J., III, S. H. Kan, M. A. Frye, H. W. Wahner, W. M. O'Fallon, and B. L. Riggs. 1989. Epidemiology of vertebral fractures in women. Am. J. Epidemiol. 129:1000-1011.

3. Gallagher, C., D. Goldgar, P. Mahoney, and J. McGill. 1985. Measurements of spine density in normal and osteoporotic subjects using computed tomography: relationship of spine density to fracture threshold and fracture index. J. Comput. Assisted Tomogr. 9:634-635.

4. Cann, C. E., H. K. Genant, F. O. Kolb, and B. Ettinger. 1985. Quantitative computed tomography for prediction of vertebral fracture risk. Metab. Bone Dis. \& Relat. Res. 6:1-7.

5. Odvina, C. V., J. E. Wergedal, C. R. Libanati, E. E. Schulz, and D. J. Baylink. 1988. Relationship between trabecular vertebral body density and fractures: a quantitative definition of spinal osteoporosis. Metab. Clin. Exp. 37:221228.

6. Genant, H. K., C. C. Glüer, and J. C. Lotz. 1994. Gender differences in bone density, skeletal geometry, and fracture biomechanics. Radiology. 190:636640.

7. Snyder, B. D., S. Piazza, W. T. Edwards, and W. C. Hayes. 1993. Role of trabecular morphology in the etiology of age-related vertebral fractures. Calcif. Tissue Int. 53:S14-S22.

8. Cooper, C. 1993. The epidemiology of fragility fractures: is there a role for bone quality? Calcif. Tissue Int. 53:S23-S26.

9. Krølner, B. 1982. Osteoporosis and normality: how to express the bone mineral content of lumbar vertebrae. Clin. Physiol. (Oxf.) 2:139-146.

10. Cummings, S. R., J. L. Kelsey, N. C. Nevitt, and K. J. O'Dowd. 1985. Epidemiology of osteoporosis and osteoporotic fractures. Epidemiol. Rev. 7:178208.

11. Mosekilde, L., and L. Mosekilde. 1990. Sex differences in age-related changes in vertebral body size, density and biochemical competence in normal individuals. Bone (Elmsford) 11:67-73.

12. Genant, H. K., G. S. Gordan, and P. G. Hoffman, Jr. 1983. Osteoporosis. I. Advanced radiologic assessment using quantitative computed tomography. West. J. Med. 139:75-84.
13. Gilsanz, V., M. I. Boechat, R. Gilsanz, M. L. Loro, T. F. Roe, and W. G. Goodman. 1994. Gender differences in vertebral size in adults: biomechanical implications. Radiology. 190:678-683.

14. Kanis, J. A., L. J. Melton III, C. Christiansen, C. C. Johnston, and N. Khaltaev. 1994. The diagnosis of osteoporosis. J. Bone Miner. Res. 9:1137-1141.

15. Block, J. E., R. Smith, C. R. Glueer, P. Steiger, B. Ettinger, and H. K. Genant. 1989. Models of spinal trabecular bone loss as determined by quantitative computed tomography. J. Bone Miner. Res. 4:249-257.

16. Eastell, R., S. L. Cedel, H. W. Wahner, B. L. Riggs, and L. J. Melton III. 1991. Classification of vertebral fractures. J. Bone Miner. Res. 6:206-215.

17. Krane, S. M., and M. F. Holick. 1991. Metabolic bone disease. In Harrison's Principles of Internal Medicine. K. J. Isselbacher, E. Braunwald, J. D. Wilson, J. B. Martin,, A. S. Fauci, and B. L. Kasper, editors. McGraw-Hill Inc., New York. 1921-1933.

18. Pacifici, R., R. C. Rupich, and L. V. Alvioli. 1990. Vertebral cortical bone mass measurement by a new quantitative computed tomography method: correlations with vertebral trabecular bone measurements. Calcif. Tissue Int. 47:215-220.

19. Kumar, S. 1988. Moment arms of spinal musculature determined from CT scans. Clin. Biomech. 3:137-144.

20. Schultz, A. B., and G. B. J. Anderson. 1981. Analysis of the loads on the lumbar spine. Spine. 6:76-82.

21. Lindh, M. 1989. Biomechanics of the lumbar spine. In Basic Biomechanics of the Musculoskeletal System. M. Nordin and V. G. Frank, editors. Lea \& Febiger, Philadelphia. 183-207.

22. Dixon, W. J., and F. J. Massey. 1983. Introduction to Statistical Analysis. McGraw Hill Inc., New York. 129-130.

23. Morrison, D. F. 1990. Multivariate Statistical Methods. McGraw Hill Inc. New York. 255-256.

24. Atkinson, P. J. 1967. Variation in trabecular structure of vertebrae with age. Calcif. Tissue Res. 1:24-32.

25. Rockoff, S. D., E. Sweet, and J. Bleustein. 1969. The relative contribution of trabecular and cortical bone to the strength of human lumbar vertebrae. Calcif. Tissue Res. 3:163-175.

26. Lindahl, O. 1976. Mechanical properties of dried defatted spongy bone. Acta Orthop. Scand. 47:11-19.

27. McBroom, R. J., W. C. Hayes, W. T. Edwards, R. P. Goldberg, and A. A White. 1985. Prediction of vertebral body compressive fracture using quantitative computed tomography. J. Bone Jt Surg. Am. Vol. 67:1206-1214.

28. Mosekilde, L., and L. Mosekilde. 1986. Normal vertebral body size and compressive strength: relations to age and to vertebral and iliac trabecular bone compressive strength. Bone. 7:207-212.

29. Biggemann, M., D. Hilweg, and P. Brinckmann. 1988. Prediction of the compressive strength of vertebral bodies of the lumbar spine by quantitative computed tomography. Skeletal Radiol. 17:264-269.

30. Brinckmann, P., M. Biggemann, and D. Hilweg. 1989. Prediction of the compressive strength of human lumbar vertebrae. Spine. 6:606-610.

31. Schultz, A. B., and G. B. J. Anderson. 1981. Analysis of loads on the lumbar spine. Spine. 6:76-82.

32. Einhorn, T. A. 1992. Bone strength: the bottom line. Calcif. Tissue Int. 51:333-339.

33. Seeman, E., J. L. Hopper, L. A. Bach, M. E. Cooper, E. Parkinson, J. McKay, and G. Jerums. 1989. Reduced bone mass in daughters of women with osteoporosis. N. Engl. J. Med. 320:554-558.

34. Morrison, N. A., J. C. Qi, A. Tokita, P. Kelly, L. Crofts, T. V. Nguyen, P. N. Sambrook, and J. A. Elsman. 1994. Prediction of bone density from vitamin D receptor alleles. Nature (Lond.). 367:284-287.

35. Gilsanz, V., M. I. Boechat, T. F. Roe, M. L. Loro, J. Sayre, and W. G. Goodman. 1994. Gender differences in vertebral body size in children and adolescents. Radiology. 190:673-677. 